\title{
Dwindling Attendance of Undergraduate Medical Students, Reasons and Possible Solutions
}

\author{
Sarita Kulbhushan Sharma ${ }^{1}$, Sunita Jayant Vagha ${ }^{2}$, Ujwala Uttamrao Ukey ${ }^{3}$, \\ Pragati Govind Rathod ${ }^{4}$, Sonali Surendra Patil ${ }^{5}$ \\ 1,3,4,5 Department of Community Medicine, Government Medical College, Nagpur, Maharashtra, India. \\ ${ }^{2}$ Department of Pathology, Jawaharlal Nehru Medical College, Sawangi, DMIMS Wardha, Maharashtra, India.
}

\section{ABSTRACT}

\section{BACKGROUND}

Student attendance is an important factor in professional development and academic performance of medical students as clinical contact and teaching are necessary to develop requisite competence. Absenteeism may negatively impact the learning process of students as well as their academic achievement. We wanted to identify reasons and possible solutions for dwindling attendance of undergraduate medical students.

\section{METHODS}

Focus group discussion was conducted with students of final MBBS for in-depth understanding of the reasons for increased absenteeism. The information gathered was collated, and on the basis of this, questionnaire was designed. Data was collected by self-administered questionnaire. Respondents were asked to rank the factors influencing absenteeism on a 5-point Likert scale. They were also asked about suggestions for improving attendance. Data was analysed using Epi Info version 7.2.1.0.

\section{RESULTS}

Main themes as identified from focus group discussion (FGD) were in the form of various factors viz. personal, teaching related, college related, hostel related and curriculum related. Important personal factors influencing absenteeism were attending class for PG entrance, mass bunk etc. Most influential curriculum related factors were vast curriculum and no proper coverage of syllabus in lecture series. Suggested measures included improved teacher student relationship, interactive teaching and conducive classrooms etc.

\section{CONCLUSIONS}

There is a need to improvise the teachings and make the educational environment more conducive.

\section{KEY WORDS}

Absenteeism, Medical Undergraduates, Reasons, Solutions
Corresponding Author: Dr. Ujwala Uttamrao Ukey, Department of Community Medicine, Government Medical College, Nagpur, Maharashtra, India. E-mail: drujwalachitre@gmail.com

DOI: $10.14260 /$ jemds $/ 2021 / 31$

How to Cite This Article: Sharma SK, Vagha SJ, Ukey UU, et al. Dwindling attendance of undergraduate medical students, reasons and possible solutions. J Evolution Med Dent Sci 2021;10(03):148-152, DOI: 10.14260/jemds/2021/31

Submission 09-10-2020,

Peer Review 20-11-2020,

Acceptance 26-11-2020,

Published 18-01-2021.

Copyright (c) 2021 Sarita Kulbhushan et al. This is an open access article distributed under Creative Commons Attribution License [Attribution 4.0 International (CC BY 4.0)] 


\section{BACKGROUND}

The goal of undergraduate medical education is to produce competent doctors with adequate medical knowledge, affective attitude towards the patients and proper clinical skills for practice. Student attendance is an important factor in the academic performance and professional development of medical students as clinical contact and teaching are necessary to develop requisite competence.1,2 Absenteeism may negatively impact the learning process and academic achievements of students. The ramifications of absenteeism are not merely limited to academic progress of the students but in addition affect the teaching-learning cycle and at times dampen the spirit and enthusiasm of teachers and other students too. It further impedes the laying of a strong foundation for a disciplined and responsible behaviour in a future medical professional. Low academic achievement assumes critical importance particularly for medical and health care providers who are concerned with decision making in situations involving urgent life and death matters. ${ }^{3,4}$ The interaction between faculty members and the students, in lectures and clinical discussions, is crucial as it is part of the professional socialization process in which students observe faculty members and recognize them as role models.5,6 This process is of great importance in learning professional attitudes / values and missing opportunities for interaction due to excessive absenteeism may hinder the development of professionalism in medical graduates. ${ }^{1,2}$ In quality terms, absenteeism is a waste of educational resources, time and human potential. The reasons for student absenteeism are similar, though the level and magnitude of each reason may differ from country to country. Lack of interest in subject matter, an un-favourable learning environment, excessive socialisation between students, perceived quality of teaching are cited as core reasons for absenteeism. The qualities of teachers, their practices and the relationship they have with their students also appear to play a significant role in absenteeism of students. ${ }^{7}$

Furthermore, improved access to online materials like videos, audios, power point presentations etc. and attending coaching classes for scoring well in postgraduate entrance exams are increasingly common reasons for students' absenteeism. In spite of implementing strict policies, the rate of absenteeism remains high and is a cause of great concern. This study specifically aimed to gain insight into reasons for absenteeism of undergraduate medical students and also attempted to gather students' opinions and suggestions for overcoming this ever-increasing problem which is taking a toll on the quality of medical education. The results of this study will help in providing a valuable insight that will open the doors for interventions to reduce absenteeism among medical students and generate evidence to bring about appropriate changes in the rules and regulations regarding attendance.

\section{METHODS}

A descriptive cross-sectional study with a mixed method approach was carried out amongst medical undergraduates at Government Medical College and tertiary care centre in central India. Although the mixed method approach is complex to carry out and requires greater expertise, it was preferred over individual approach as combination of both qualitative and quantitative methods balances the limitations of each one, provides stronger evidence and increases the confidence in the findings. Final MBBS part-I students have already experienced various teaching-learning activities and are in a better position to express their viewpoints as compared to their counterparts in first and second year of MBBS. Moreover, the present study being carried out in community medicine department, these students were easily accessible to the researchers. Thus, convenience sampling was resorted to and all 201 students of final MBBS part 1 on roll were included in the present study. Ethical clearance was obtained from the Institutional Ethics Committee of the institute. Written informed consent was taken from the study subjects after apprising them of the nature and the purpose of the study. Study subjects were ensured about confidentiality and anonymity and personal information of any form like name, roll number, contact number etc. was not included in the questionnaire.

Focus group discussions were carried out with students of final MBBS for in-depth understanding of the reasons for increased absenteeism. For analysis of the FGDs all the comments from the FGDs were transcribed and different themes and subthemes were identified. Based on this, the factors influencing absenteeism in medical undergraduates were categorized as personal factors, teaching related factors, college related factors, hostel related factors and curriculum related factors. The information gathered from the FGDs, was collated and on the basis of this a questionnaire for further quantitative data collection was designed by the lead researcher and was reviewed by an expert panel for content validity and reliability. This questionnaire was pretested by carrying out a pilot study on 50 final MBBS (part II) students and modified accordingly.

Data was collected from third MBBS (part I) students using this pretested and pre validated self-administered questionnaire. Respondents were asked to rank these factors on a 5-point Likert scale with a score of 5 representing a strongly positive influence, score of 1 representing a strongly negative influence, and a score of 3 indicating neutral influence on attendance. Study subjects were also asked about their opinions / suggestions for improvement in the attendance.

\section{Statistical Analysis}

The data was entered in Microsoft Office Excel and was further analysed using Epi Info version 7.2.1.0. Mean, standard deviation (SD) and percentage were calculated for quantitative data.

\section{RESULTS}

Of the 201 students, 197 returned the filled questionnaire giving a response rate of $98.01 \%$. Of the 197 students, 97 (49. $24 \%$ ) were male and 100 (50.76\%) were female. Their mean age was $21.25 \pm 0.79$ years with the range being 21 to 24 years.

The main themes and sub themes arrived at from the focus group discussions along with the comments verbatim are seen 
in Table 1.

\begin{tabular}{|c|c|c|}
\hline Theme & Subtheme & Comments Verbatim \\
\hline Personal Factors & $\begin{array}{l}\text { Attending class for PG entrance } \\
\text { Going to bed late due to studies } \\
\text { Prefer self-studies } \\
\text { Mass bunk }\end{array}$ & $\begin{array}{c}\text { "We need to miss lecture for attending PG entrance classes" } \\
\text { "Pressure from the seniors to proceed on mass bunk or miss classes and do self-studies leads to } \\
\text { greater absenteeism" } \\
\text { "If there is a death or illness in the family, obviously I cannot attend." } \\
\text { and fatigue leading to greater absenteeism" } \\
\text { "Poor time management like spending to decreased sleep } \\
\text { "We do not attend lectures because they are boringand not interactive" } \\
\text { "Majority of the lectures are useless, better material available online" } \\
\text { "At times, we have to prepare for a test and therefore, we stay back and don't attend lectures" } \\
\text { "When you have more interesting things to do (e.g. cricket, movie, lunch with friends) who would } \\
\text { stay back for a } \\
\text { boring lecture" } \\
\text { "We bunk classes because "proxy" is possible and the main objective is attendance, which is } \\
\text { fulfilled" }\end{array}$ \\
\hline $\begin{array}{l}\text { Teaching Related } \\
\text { factors }\end{array}$ & $\begin{array}{l}\text { Monotonous teaching } \\
\text { Less focus on practical applicability } \\
\text { Non-interaction } \\
\text { Poor } \\
\text { teaching skills }\end{array}$ & $\begin{array}{c}\text { "More stress on practical approach of teachinglearning rather than merely imparting theoretical } \\
\text { knowledge" } \\
\text { "Small group teaching should be preferred with appropriate use of advanced teaching methods, } \\
\text { videos, chalk and talk along with power pointpresentations" }\end{array}$ \\
\hline $\begin{array}{l}\text { College Related } \\
\text { Factors }\end{array}$ & $\begin{array}{l}\text { Poor infrastructure } \\
\text { No provision of preparation leave } \\
\text { Classroom ambience } \\
\text { Frequent last moment cancel of class }\end{array}$ & $\begin{array}{c}\text { "Conducive classroom atmosphere (Proper ventilation, AC \&Audio system) will facilitate better } \\
\text { learning and will } \\
\text { motivate them to attend classes regularly" }\end{array}$ \\
\hline $\begin{array}{l}\text { Hostel Related } \\
\text { Factors }\end{array}$ & $\begin{array}{l}\text { Sanitation problems } \\
\text { Food related problems } \\
\text { Nonfunctional washrooms } \\
\text { Mosquito menace }\end{array}$ & $\begin{array}{l}\text { "Improved hostel facilities like food, water and sanitation will go a long way in improving the } \\
\text { students' attendance in classes" }\end{array}$ \\
\hline Curriculum Related & $\begin{array}{c}\text { Sanitation problems } \\
\text { Food related problems } \\
\text { Nonfunctional washrooms } \\
\text { Mosquito menace, vast curriculum } \\
\text { Lecture series not covering the entire } \\
\text { syllabus } \\
\text { Lectures not } \\
\text { catering of future }\end{array}$ & $\begin{array}{c}\text { "Improved hostel facilities like food, water and sanitation will go a long way in improving the } \\
\text { students' attendance in classes" } \\
\text { "Teaching should cover entire syllabus and also should focus on preparation in view of PG } \\
\text { entrance examination" }\end{array}$ \\
\hline \multicolumn{3}{|r|}{ Table 1. Main Themes and Subthemes } \\
\hline
\end{tabular}

Personal factors, teaching related factors, college related factors, hostel related factors and curriculum related factors were the main themes identified as important reasons for absenteeism.

The scores for each of the items for personal factors as marked by the study participants on a 5-point Likert scale were averaged and they are shown in Table 2 . The important personal factors influencing absenteeism were attending class for postgraduate entrance exam, going to bed late due to studies, preferring self-studies, mass bunk, illness of self and going to bed late due to social media, all having a mean score above three.

\begin{tabular}{|c|c|c|c|}
\hline Personal Factors & $\begin{array}{l}\text { Mean Score } \\
\text { (SD) }\end{array}$ & Personal Factors & $\begin{array}{l}\text { Mean Score } \\
\text { (SD) }\end{array}$ \\
\hline $\begin{array}{c}\text { Attending class for PG } \\
\text { entrance }\end{array}$ & $3.62(1.20)$ & Leisure activities & $2.69(1.42)$ \\
\hline $\begin{array}{c}\text { Going to bed late due to } \\
\text { studies }\end{array}$ & $3.45(1.06)$ & Depression \& anxiety & $2.64(1.34)$ \\
\hline Prefer self-studies & $3.3(1.19)$ & Home sick & $2.6(1.34)$ \\
\hline Mass bunk & $3.16(1.20)$ & $\begin{array}{l}\text { Illness of family } \\
\text { members }\end{array}$ & $2.40(1.25)$ \\
\hline Illness of self & $3.15(1.26)$ & $\begin{array}{c}\text { Lack of interest towards } \\
\text { college }\end{array}$ & $2.3(1.20)$ \\
\hline $\begin{array}{l}\text { Going to bed late due to } \\
\text { social media }\end{array}$ & $3.1(1.37)$ & $\begin{array}{c}\text { Already attending tuition } \\
\text { classes }\end{array}$ & $2.3(1.31)$ \\
\hline Menstrual problems & $3.06(1.35)$ & Language problem & $1.87(1.12)$ \\
\hline Extracurricular activities & $2.72(1.25)$ & Dislike for medical field & $1.69(1.03)$ \\
\hline Other family issues & $2.96(1.08)$ & Romantic relation & $1.65(1.13)$ \\
\hline Low confidence level & $2.7(1.34)$ & Substance abuse & $1.22(0.63)$ \\
\hline \multicolumn{4}{|c|}{ Table 2. Personal Factors Influencing Absenteeism ( $N=197)$} \\
\hline
\end{tabular}

Monotonous teaching, less focus on practical applicability, lack of interaction and poor teaching skills were the predominant teaching related factors influencing absenteeism (Figure 1). Poor infrastructure, no provision of preparation leave and poor classroom ambience were identified as the main college related factors influencing absenteeism (Figure 2).

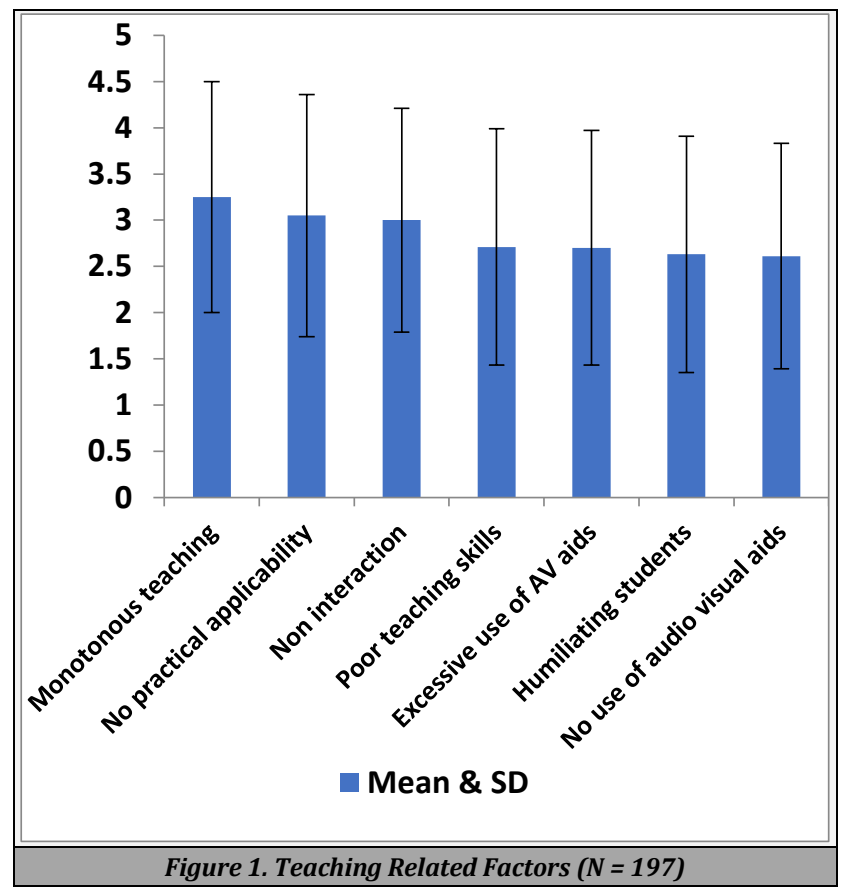




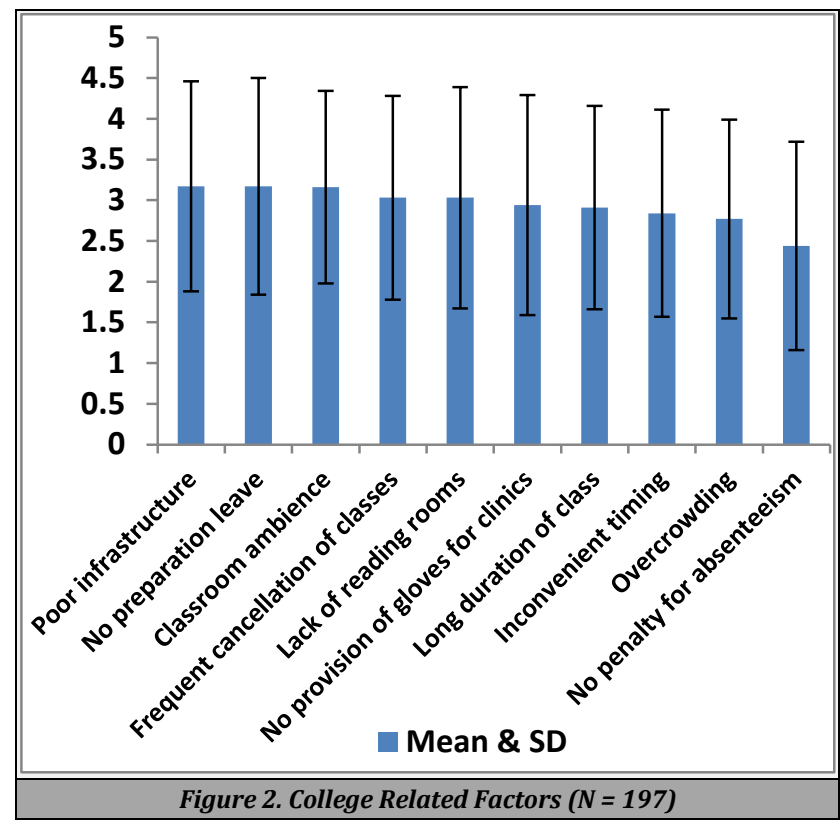

Salient hostel related factors identified were sanitation problems (3.6), food related problems (3.52), non-functional washrooms (3.47), mosquito menace (3.43) and water scarcity (3.29). Most influential curriculum related factors were vast curriculum (mean score of 3.63), no proper coverage of syllabus in the lecture series (3.37) and lectures not catering to future needs (3.09).

On comparing the mean scores for each category of factors influencing absenteeism, it was observed that the main influencers were hostel related and curriculum related factors with mean scores of 3.36 and 3.05 respectively. Other factors like college related, teaching related and personal factors had a mean score of 2.95, 2.85 and 2.67 respectively.

Suggestions given for improvement of attendance are shown in table 3. Improved teacher student relationship, small group teaching, conducive classrooms, provision of preparation leave, more stress on practical application of knowledge were some of the suggestions given by the students to improve the attendance of medical undergraduates.

\begin{tabular}{|cc|}
\hline Suggestions & $\begin{array}{c}\text { Frequency N = 197 Number } \\
\text { (\%) }\end{array}$ \\
Improved teacher student relationship & $175(88.83)$ \\
Batch wise lectures (small group teaching) & $165(83.76)$ \\
Conducive Classrooms & $147(74.62)$ \\
Provision of preparation leave & $146(74.11)$ \\
More stress on practical application of & $145(73.60)$ \\
knowledge & $130(65.99)$ \\
Time and stress management & $130(65.99)$ \\
Sports in the curriculum & $127(64.47)$ \\
Appropriate use of audio-visual aids & $106(53.81)$ \\
Promotion of Integrated teaching & $98(49.75)$ \\
Teachers should refrain from humiliating and \\
insulting students
\end{tabular}

\section{DISCUSSION}

Student absenteeism is a worldwide problem for university education and the field of medicine is no exception. In spite of implementing strict policies, the rate of absenteeism in medical colleges remains a phenomenon that is on constant rise in universities worldwide. The implications of absenteeism are clearly delineated in the literature but reasons contributing to absenteeism for lectures and especially clinical postings are not explicitly highlighted, and neither any contextual solutions to combat this issue are provided. This study was designed to identify reasons and possible solutions for absenteeism of undergraduate medical students.

Most common personal factors identified were attending class for PG entrance, going to bed late due to studies, preferring self-studies, mass bunk, illness of self, going to bed late due to excessive use of social media etc. Similar findings were also reported by other authors. $5,8,9$ Present study also found out preparing for another test, extracurricular activities and other miscellaneous commitments as "different priorities" for being absent. Peer pressure is also known to be a very strong factor in shaping young adults' behaviours and plays a strong role as a cause of absenteeism. Monotonous teaching and less focus on practical applicability were important teaching related factors influencing absenteeism.

Students found lectures boring and of low value because of lack of interaction, condescending attitude of teachers and inappropriate learning environment. A high number of students remain absent in the pre examination period, which could be explained by their allotting of this time for more intensive study before the exams. Preparing for another examination, inconvenient class schedule, lack of interest in the subject, dislike for teaching style and the ease of understanding the subject matter without guidance were the major reasons as noted by Chaudhry SH et al. \& Sharmin T et al. ${ }^{10,11}$ Another common reason for absenteeism is sickness. Unexpected life situation can occur like illness of self or that of a family member or some other family problem which force the student to miss classes. Poor lecture content or presentation skills make the students lose their concentration and this affects the attendance of the students. With the increasing advancement in technology access to knowledge is not a big deal. Students have access to electronic study material hence they miss classes.

College related factors identified were non-conducive educational environment, no provision of preparation leave, poor classroom ambience etc. Salient hostel related factors identified were sanitation problems, food related problems etc. Most influential curriculum related factors were vast curriculum and no proper coverage of syllabus in the lecture series similar to the findings of other studies. ${ }^{6,12,13}$

Various measures suggested by the students to counter absenteeism include; improved teacher student relationship, interactive teaching, small group teaching with conducive classrooms, provision of preparation leave and more stress on practical applicability of knowledge. Our results are in coherence with the findings of other studies. ${ }^{14,15}$

\section{CONCLUSIONS}

The results of this study provide a valuable insight into reasons of absenteeism in medical students and interventions to reduce the same with appropriate changes in the rules and regulations regarding attendance. The main influencing 
factors identified were vast and ill-defined curriculum, ineffective teaching, non-conducive learning environment and inflexible time table hampering quality learning. Suggested rectification measures included improved teacher student relationship, small group teachings in conducive classrooms, provision of preparation leave and more stress on practical application of knowledge. Students as well as faculty need to be made aware of the problem and its short- and long-term consequences for the students and society at large. Also, there is a need to improvise the teachings and make the educational environment more conducive. Early detection and prevention might prevent unwanted consequences of absenteeism on medical student's academic performance and professional development. Medical colleges should strictly reinforce the attendance policy as an effort to overcome this colossal problem.

Data sharing statement provided by the authors is available with the full text of this article at jemds.com.

Financial or other competing interests: None.

Disclosure forms provided by the authors are available with the full text of this article at jemds.com.

\section{REFERENCES}

[1] Tripura K, Das R, Saha N. Attitude of medical students towards the reasons of absenteeism in a medical college of Tripura. IOSR J Dent Med Sci 2015;14(11):110-2.

[2] Qutub MF, Bafail MA, Alomari AS, et al. Absenteeism among Saudi Medical Students. Egypt J Hosp Med 2018;70(8):1248-53.

[3] Haritha T. Undergraduate medical students ' absenteeism during dermatology, venereology and leprosy clinical postings. Int J Contemp Med Res 2016;3(11):3376-81.

[4] Nevins EJ, Moori PL, Alexander L, et al. Could attendance at medical school be improved? a prospective study of medical education at the university of liverpool: study of attendance at a UK medical school. MedEdPublish 2016;1-5.
[5] Hafeez K, Khan MLZ, Jawaid M, et al. Low Attendance in lectures at medical colleges of Karachi - a cross sectional survey. J Postgr Med Inst 2014;28(2):161-4.

[6] Gul R, Khan HM, Alam SR, et al. Absenteeism among medical undergraduate students. J Med Sci 2016;24(1):16-8.

[7] Bati AH, Mandiracioglu A, Orgun F, et al. Why do students miss lectures? A study of lecture attendance amongst students of health science. Nurse Educ Today 2013;33(6):596-601.

[8] Desalegn AA, Berhan A, Berhan Y. Absenteeism among medical and health science undergraduate students at Hawassa University, Ethiopia. BMC Med Educ 2014;14:81.

[9] Maulik V, Anup V, Chinmay S, et al. Attendance, attitudes and academic performance: a study on first year MBBS students attending physiology classes. Int J Med Sci Educ 2016;3(1):31-7.

[10] Chaudhry SH Iqbal J. Absenteeism of medical students from subspecialty clinical rotations: a qualitative study. J Coll Physicians Surg Pak 2019;29(1):45-50.

[11] Sharmin T, Azim E, Choudhury S, et al. Reasons of absenteeism among undergraduate medical students: a review. AKMMC J 2017;8(1):60-6.

[12] Ahmad M, Rahman FN, Shawon MMI, et al. Effect of class attendance on medical student's academic performance an observational study. Faridpur Med Coll Journal 2017;12(2):58-63.

[13] Alhabi OHA, Abukhelaif AEE, Dokhaikh FAA, et al. Absenteeism and lateness among Saudi Medical Students at Albaha University, Saudi Arabia: an observational study. IOSR J Res Method Educ 2017;7(6):38-41.

[14] Qureshi MI, Ahmad A. Medical students' perspective on absenteeism and its remedies. Pak Armed Forces Med J 2019;69(2):332-9.

[15] Rao BT, Valleswary K, Nayak MSDP, et al. Reasons for absenteeism among the undergraduate medical students attending for theory classes in Rajiv Gandhi Institute of Medical Sciences (RIMS) Ongole, Prakasam District of Andhra Pradesh: a self review. IOSR J Res Method Educ 2016;6(4):11-9. 